\title{
Survey of respiratory sounds in infants
}

\author{
H E Elphick, P Sherlock, G Foxall, E J Simpson, N A Shiell, R A Primhak, M L Everard
}

\begin{abstract}
Background-Over the last decade there has been an apparent increase in childhood wheeze. We speculated that much of the reported increase may be attributed to the term wheeze being adopted by parents to describe a variety of other forms of noisy breathing.

Aims - To investigate terminology used by parents to describe their children's breath sounds.

Methods-An interview was carried out with the parents of 92 infants with noisy breathing, beginning with an open question and then directed towards a more detailed description. Finally, the parents were asked to choose from a wheeze, ruttle, and stridor on imitation by the investigator and video clips of children.

Results-Wheeze was the most commonly chosen word on initial questioning (59\%). Only $36 \%$ were still using this term at the end of the interview, representing a decrease of one third, whereas the use of the word ruttles doubled.

Conclusions-Our results reflect the degree of inaccuracy involved in the use of the term wheeze in clinical practice, which may be leading to over diagnosis. Imprecise use of this term has potentially important implications for therapy and clinical trials.
\end{abstract}

(Arch Dis Child 2001;84:35-39)

Keywords: respiratory sounds; wheeze

Over the past decade epidemiological studies have suggested that early childhood wheeze is a common problem. ${ }^{12}$ In a questionnaire based prospective study, Martinez et al found that one third of children under the age of 3 years had had at least one episode of wheeze diagnosed by a doctor. ${ }^{3}$ However, the epidemiological study of wheeze depends on accurate reporting. A major weakness of many studies is that they simply ask whether or not a child has

Paediatric Respiratory Unit, Sheffield Children's Hospital, University of Sheffield, Western Bank, Sheffield S10 2TH, UK H E Elphick

P Sherlock

G Foxall

E J Simpson

N A Shiell

R A Primhak

M L Everard

Correspondence to:

Dr Everard

m.1.everard@sheffield.ac.uk

Accepted 9 August 2000 as a "ruttle". This sound is lower in pitch with a rattling quality and lacking any musical features. Characteristically parents are able to feel this noise as a vibration over the baby's back in contrast to classical wheeze in which no such transmitted vibrations are evident. The source of this sound is unclear, but may reflect excessive secretions in the central and extrathoracic airways or alternatively may be related to airways tone in the central and upper airways. We have previously shown objectively that these sounds are quite distinct, using a breath sounds analysis technique. ${ }^{6}$

One study assessing the prevalence of a variety of symptoms in 298 infants less than 6 months of age in the community found that noisy breathing was very common, with $30 \%$ of parents reporting noisy breathing in the previous 24 hours and $11 \%$ of the infants said to have had noisy breathing from birth. ${ }^{7}$ On closer questioning the investigators determined that stridor accounted for $1 \%$, upper airways noises $93 \%$, and classical wheeze only $2 \%$ of the total. The vast majority of infants therefore had snuffly or upper airway noises; many of the latter are likely to have ruttles.

The aim of this study was to investigate the terminology used by parents in both hospital and community settings to describe their children's breath sounds. We were particularly interested in their use of the terms "wheeze" and "ruttles". Our hypotheses were: firstly, that parents use the term wheeze to describe other forms of noisy breathing, including ruttles, unless directed specifically to describe the noise in more detail; and secondly, that this feature is more pronounced in those parents that receive hospital contact, perhaps because they become conditioned to use the word that they perceive to be a more acceptable medical term in the belief that they are being more helpful to the medical staff.

\section{Methods}

A questionnaire based interview was carried out, in two stages, with the parents of 92 children under the age of 18 months. Approval for the study was obtained from the local ethics committee and informed consent was obtained from the infants' parents.

During the first stage, the parents of any child under the age of 18 months admitted to the wards or referred to the outpatients clinic at Sheffield Children's Hospital with any form of noisy breathing were asked to take part in the study. Inpatients were selected from admission lists each morning; outpatients were identified from the clinical notes prior to their visit to the clinic. The only exclusion criterion was the inability to speak the English language.

The interview began by allowing parents to openly state, without prompting with any suggestions, the words they would use to describe their child's breathing. We have termed this as "open" questioning. Following this, parents 
were asked to give a more detailed description of the words used; this was considered as "detailed" questioning. Thirdly, parents were asked to choose from a list of 10 example words. More than one word could be chosen. The list of words included: wheeze, ruttle, rustle, squeak, whistle, ruckle, snuffle, whoop, rattle, and snort.

The next two questions were used to try to differentiate between a wheeze and a ruttle. The parents were asked whether they thought the noise was coming from the chest, nose, or throat; and secondly, whether they could feel vibrations on the baby's chest in association with the noise.

Finally, the parents were shown an imitation and/or a video recording of a wheeze, a "ruttle", and a stridor and were asked to choose the sound that most resembled the noise made by their child. The imitations were carried out by one of the investigators (PS) and the video clips were made of children under 18 months previously admitted to the hospital, with their parents' consent. The noises demonstrated by each method were consistently agreed on by two senior paediatricians before inclusion in the study.

As the second stage of the study, a postal questionnaire was sent out to parents of 203 children from general practice lists in Sheffield covering a range of social backgrounds. The names of all children under 18 months were obtained by computer search and a standard letter explaining the purpose of the study was sent to the parent(s) of each child. They were asked whether their child had noisy breathing and, if so, whether they would be willing to participate in the study. All responders with noisy breathing were contacted and an appointment was made with the first 30 sets of parents, to conduct the same questionnaire interview as above, including both the imitation and the video recording.

STATISTICAL ANALYSIS

Sensitivity, specificity, and positive predictive value analyses were performed to compare the accuracy and usefulness of the terms used to

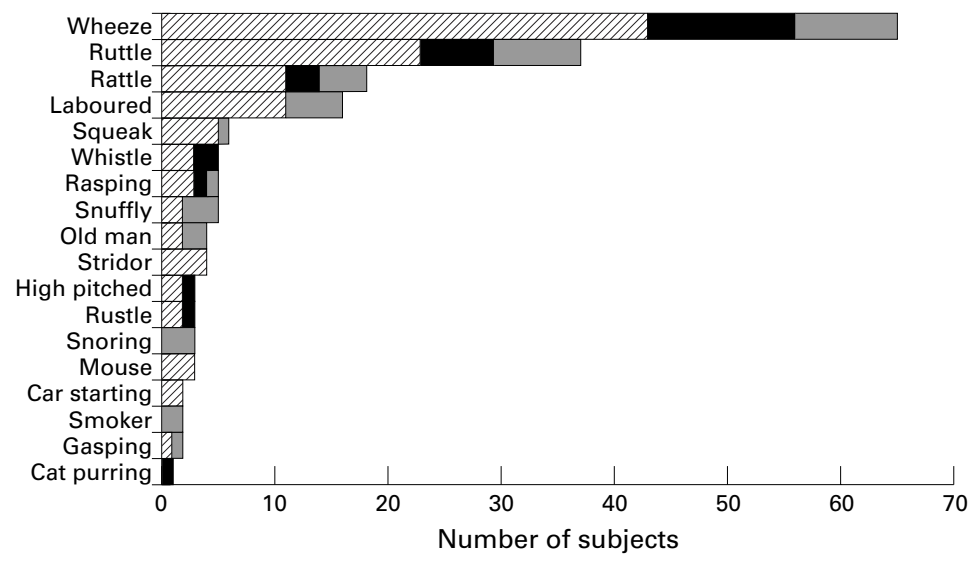

Inpatients $\square$ Outpatients $\square$ Community

Figure 1 Frequency of the 18 terms most commonly used by patents to describe noisy breathing. There may be more than one word per infant. The number of children is expressed as a percentage as not every child was subjected to both imitation and video.
Table 1 Diagnoses of the group of inpatients with noisy breathing

\begin{tabular}{lc}
\hline Diagnosis & $\begin{array}{l}\text { Number of } \\
\text { children affected }\end{array}$ \\
\hline Asthma & 8 \\
Wheeze associated viral episode & 16 \\
Pneumonia & 3 \\
Bronchiolitis & 10 \\
Viral upper respiratory tract infection & 3 \\
Croup & 2 \\
Subglottic stenosis & 2
\end{tabular}

describe the children's noisy breathing. $\chi^{2}$ analysis was used as a test of comparative data and the level of significance was taken at $\mathrm{p}<0.05$.

\section{Results}

In total, the parents of 92 children were interviewed: 44 inpatients, 19 outpatients, and 29 in the community. All parents that were approached directly agreed to take part in the study. Of the parents approached by postal questionnaire, 62 responded and of those, 39 $(63 \%)$ had children with noisy breathing. Two parents were excluded because of a poor understanding of the English language. The age range of the children seen in hospital was 0-18 months, mean 6.8 months, with $61 \%$ boys and $39 \%$ girls. In the community the mean age was 11 months, age range 1-18 months, $37 \%$ boys. Table 1 shows the range of diagnoses for the inpatients.

Figure 1 shows frequency of the terms most commonly used by the parents. The most common word offered by parents was "wheeze" (65\%). When parents were asked what they meant by the word wheeze, there was a wide variation in the answers given. The word "whistle" was used to qualify the description of wheeze in $8 / 65(12 \%)$ cases. Four parents used the word "tight" and three used "high pitched". On one occasion, wheeze was described as a "musical sound".

The second most common words were ruttle, ruckle, and rattle (40\%). As the words ruttle and ruckle are probably terms that are peculiar to Sheffield, we have combined the three words in our analysis. On detailed questioning, "bubbling" or "breathing through fluid" were strongly associated with the use of these words $\left(p<0.001, \chi^{2}\right)$.

Other terms used included more descriptive phrases such as "tiger roaring", "like a Labrador", "like a pair of bellows that's not very efficient", "like a dirty phone call", "smokes 40 a day", and "like a little pig".

There was no significant association using $\chi^{2}$ analysis between the noise finally chosen by the parents from the video and the site within the respiratory system from which they thought the sound was generated. Of those that chose wheeze, $62 \%$ thought the noise came from the chest, compared to $25 \%$ who thought it was the upper airways (including throat, "windpipe", upper chest, and nose) and $13 \%$ who thought it came from both. Of those that chose ruttles, $51 \%$ thought the noise came from the chest, $34 \%$ from the upper airways, and $12 \%$ both; $2 \%$ said they did not know. Thirty four per cent 

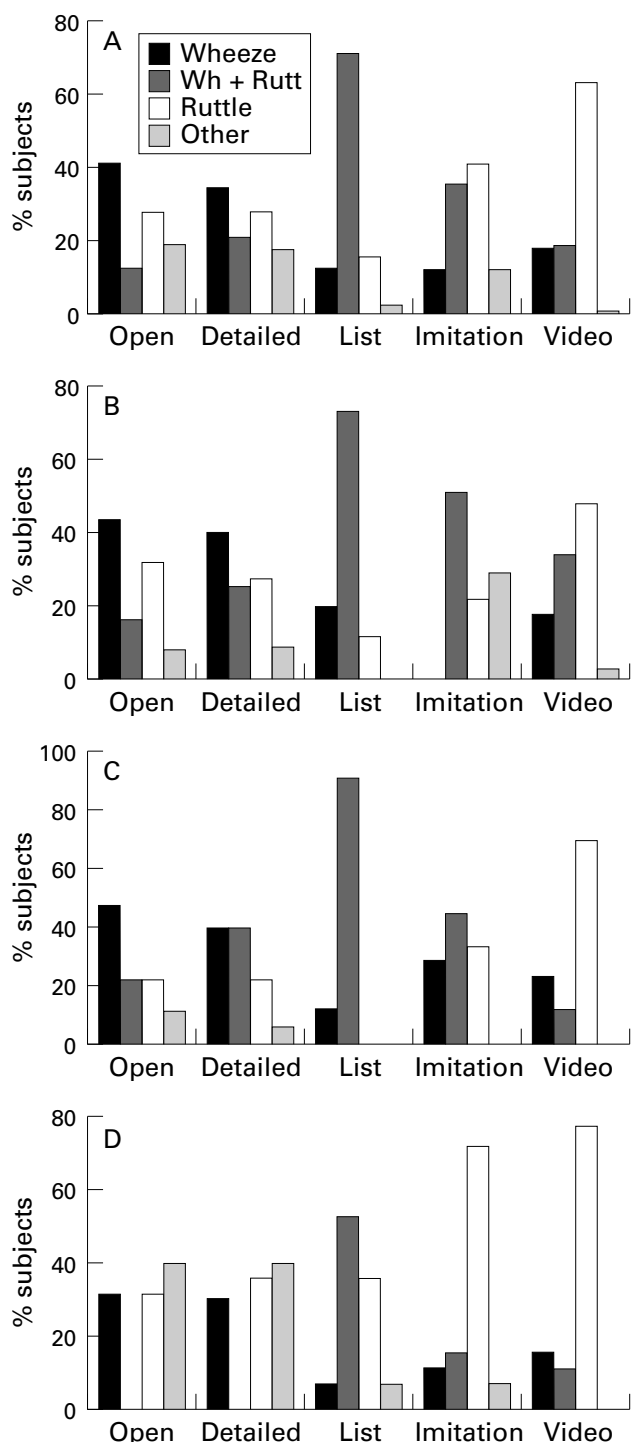

Figure 2 Changing use of the words wheeze and ruttles with increasingly detailed interviewing. (A) All subjects $(n=92)$. (B-D) Subgroups: $(B)$ inpatients $(n=44)$; (C) outpatients $(n=19)$; (D) community $(n=29)$.

of the parents that chose ruttles said they could feel vibrations on the baby's chest compared to $12 \%$ of those who chose wheeze.

Figure 2 represents the parents' use of the two most common words, wheeze and ruttle, while increasing the detail of the questioningfrom open question through to the use of imitation and video clips. Figure $2 \mathrm{~A}$ shows the results from the entire group of 92 infants. Overall, 53\% described their children as having wheeze at the beginning of the interview; how-

Table 2 Comparison of the use of the words wheeze and ruttles with final choice of noise from video recordings

\begin{tabular}{lllll}
\hline & & \multicolumn{3}{l}{ Word given on showing video } \\
\cline { 3 - 5 } & & Yes & No & Total \\
\hline Wheeze & & & & \\
Word given on open questionning & Yes & 17 & 15 & 32 \\
& No & 10 & 32 & 42 \\
Ruttles & Total & 27 & 47 & 74 \\
Word given on open questionning & & & & \\
& Yes & 26 & 3 & 29 \\
& No & 32 & 13 & 45 \\
& Total & 58 & 16 & 74 \\
\hline
\end{tabular}

ever, only $36 \%$ were still using this term by the end of the interview, representing a decrease of one third of those originally using the term. There was an increase in the use of the word ruttles from $40 \%$ at the beginning of the interview to $81 \%$ at the end.

When looking specifically at the change from wheeze to ruttle in the individual groups (fig 2B-D), in the inpatient group, $59 \%$ of parents mentioned wheeze at the beginning of the interview but only $50 \%$ still used wheeze at the end. There was an increase in the use of the term ruttles from $48 \%$ to $80 \%$ at the end. In the outpatients, $68 \%$ offered wheeze at the beginning of the interview but only $33 \%$ at the end. Therefore $50 \%$ of parents who described their child as wheezing initially had stopped using the term at the end of the interview. There was a rise in the word ruttles from $42 \%$ to $78 \%$. In the community, $31 \%$ used the term wheeze at the beginning and $24 \%$ at the end, with an increase in ruttles from $69 \%$ to $86 \%$.

In the 74 parents shown a video recording, we compared the use of each of the words wheeze and ruttles on open questioning with the noise chosen from the video (table 2). The sensitivity, specificity, and positive predictive value of the word wheeze as the first word to be offered were $0.63,0.68$, and 0.53 respectively. The sensitivity, specificity, and positive predictive value of the word ruttle were $0.45,0.81$, and 0.90 respectively.

\section{Discussion}

Our results show that $53 \%$ of parents of children with noisy breathing volunteer the word "wheeze" to describe the noises when questioned without any prompting or further description of the noise. Only 36\% were still using the term wheeze by the time they were shown a video clip, after increasingly detailed interviewing. This reflects the degree of inaccuracy involved in the use of this term in clinical practice, and may lead to over diagnosis of wheeze in infants.

A variety of imaginative and descriptive terms were offered by parents on more detailed questioning; after wheeze the second most common term was a variation of ruttle, ruckle, and rattle, which had a highly significant correlation with the description of bubbling or fluid. Although these terms were only offered by $40 \%$ of parents initially, they were the most commonly chosen from the video clips $(81 \%$ overall). This confirms our impression that ruttles are a common finding, but that the term is not being adequately used in clinical practice to distinguish this noise from the classical wheeze.

From our experience, ruttling can be present from birth or commence after a bronchiolitic or other viral induced respiratory illness. It is common in the first year of life but rarely heard after 15-18 months of life. The underlying mechanism is unclear but may reflect excessive secretions in central and extrathoracic airways or may be related to airways tone. It often follows viral infections which will induce glandular hyperplasia and disruption of cilial function that can persist for months even in the absence 
of further insults. This may lead to a relative excess of secretions in the airways and contribute to the presence of ruttles. The symptoms are frequently intermittent, can be exacerbated by viral infections, and do occur at night.

It is important to distinguish these sounds from wheeze for a number of reasons. As ruttles are such a frequent symptom in young children in a community setting this tendency to call audible respiratory noises "wheeze" may lead to significant over reporting of wheeze when parents are completing questionnaires as part of an epidemiological study. Failure to recognise the existence of these distinct sounds may result in many young children in the community being labelled as having wheeze when in fact they ruttle.

Since wheeze and ruttles are both common in early life, it is not surprising that they occasionally coexist in the same child. However, it appears likely that they have different aetiologies, natural histories, and probably different responses to therapy, which will influence both clinical practice and the outcome of clinical trials. Our clinical impression is that patients with ruttles frequently respond well to ipratropium bromide. However, as ruttles generally resolve spontaneously in the second year of life, the short term prognosis is good and reassurance is generally all that is required.

From our results, the parents that were most likely to change their description from the term wheeze to ruttles were those whose children were being seen in outpatient clinics. This may be because this is the first contact with hospital medical staff, and they perhaps think that the term wheeze is a "medical" term that the doctor will expect to hear or will use him/herself.

It is likely that patients admitted to hospital will have greater incidence of classical wheeze as this is associated with airways obstruction which may be evident clinically with tachypnoea and recession; therefore it was not surprising to find that parents of such children were less likely to alter their description after observing the video. Ruttles, while engendering anxiety in many parents, are not associated with significant airways obstruction and are therefore far less likely to contribute to hospitalisation.

The parents of the infants that were seen in the community were the most consistent in their descriptions. Over a third said neither wheeze nor ruttles on initial questioning but described snuffly or heavy breathing, suggesting upper rather than lower airway problems, and this group had the highest incidence of ruttles and upper airway noises overall. However, $29.5 \%$ did offer the term wheeze, and this figure is considerably higher than a previous study by Thornton et al, which asked parents in the community to describe noisy breathing, and found wheeze in only $2 \%{ }^{7}$ This may be because we were looking at an older group of children up to 18 months of age compared to Thornton's group of less than 6 months.

Many large prospective studies ${ }^{1}$ showing early childhood wheeze have found that most become wheeze free later in childhood. The group that do not have persistent wheeze are less likely to have increased bronchial hyperreactivity or atopy in later years. ${ }^{2}{ }^{3}$ As no detailed description of wheeze has been offered in these studies it is possible that these groups include infants with ruttles or other forms of noisy breathing. These studies have not looked closely at what the parents are actually describing when they use the term wheeze. One study by Luyt et al looked at characteristics of wheeze in preschool children such as severity, precipitating factors, and family history, but not at what parents actually meant by the term wheeze itself. ${ }^{8}$ The group did offer an explanation of wheeze, although part of the criteria included "a noise coming from the chest and not the throat". We have shown that there is considerable confusion among parents about the area within the respiratory system from which different sounds originate.

A number of studies have used the term "whistling " to qualify wheeze as a way of helping parents to understand what is being asked, and these include the widely used Isaac questionnaire. $^{9}$ Our study found that parents only used whistle to describe wheeze in $12 \%$ of cases. Cane et al reviewed these studies and found that 11 out of 12 included the term "whistle" to describe wheeze, and seven specified that the noise came from the chest, not the throat. ${ }^{10}$ As mentioned above, these attempts to define wheeze may cause additional confusion to parents and may either over or under estimate the numbers with true classical wheeze. The same study asked parents what they meant by wheeze and found that the majority associated the noise with other features such as difficulty breathing. In this study, only $11 \%$ of parents mentioned the word "whistle", a similar proportion to our own study; $43 \%$ stated that they could feel something in the chest, compared to $56 \%$ of our group. However, in our study, $74 \%$ of these parents described their child's noisy breathing as ruttles, compared to $26 \%$ who used the term wheeze.

We have used three other methods to assist parents in understanding what we mean by the terms used: a list of 10 words; imitations of wheeze, ruttle, and stridor by the investigator; and video clips of the same three noises made by infants of a similar age to those being studied. Giving parents a list of words did not seem to be useful in finding out exactly what they meant as they frequently chose most words that were offered to them. Parents reported that they found it difficult to interpret noises being imitated by an adult and to compare them with noises made by infants. Of the 44 inpatients, two parents used the term stridor to describe their child's breathing from the outset. These were infants with a diagnosis of subglottic stenosis and therefore their parents had had a high exposure to medical terminology. However, $29 \%$ of the inpatients chose stridor from the three options given to them on imitation. This may be because parents mistook the sound for a wheeze, not appreciating the significance of an expiratory compared to an inspiratory noise. The use of video clips was felt to be the most accurate method of assessing the children's 
respiratory noises and it has been suggested previously that this method may be useful in training health workers and in standardising definitions of simple respiratory signs. ${ }^{11}$

With no definitive gold standard for the definition of breath sounds in young children, terminology is confusing, both for medical staff and for parents. Similar problems have arisen in the past with the use of "doctor diagnosed asthma" as a measure of prevalence in the community as there is no epidemiological gold standard for an acceptable definition of asthma, and the presence of current wheeze has been suggested as a more accurate measure. ${ }^{12}$ In the light of our results, we propose that even this measure is inaccurate unless we can clarify the definition of the term wheeze itself.

Our results support the hypothesis that parents of young children are using the word wheeze inappropriately, both in the hospital setting and in the community. Without any prompting, parents were more likely to offer the word wheeze. However, when shown video recordings, they were more likely to change their description to include ruttle. We propose that one reason for the increase in young children with reported wheeze over the last decade is that parents are using the term "wheeze" to describe other sounds such as "ruttles". This highlights the need for accurate history taking, as parents' initial response may be to use words which they perceive as being a medical term.
The responsibility lies with the doctor to ensure that interpretation of the language used by parents reflects accurately the noise that they mean to describe. Imprecise use of the term wheeze by parents has potentially important implications for clinical trials as well as for the diagnosis and therapy of respiratory disease.

1 Park ES, Golding J, Carswell F, Stewart-Brown S. Preschool wheezing and prognosis at 10. Arch Dis Child 1986;61: $642-6$.

2 Sporik R, Holgate ST, Cogswell JJ. Natural history of asthma in childhood - a birth cohort study. Arch Dis Child 1991;66:1050-3.

3 Martinez FD, Wright AL, Taussig LM, et al. Asthma and wheezing in the first 6 years of life. $N$ Engl 7 Med 1995;332: 133-8.

4 Pasterkamp H, Carson C, Daien D, Oh Y. Digital respirosonography: new images of lung sounds. Chest 989:96:1405-12.

5 Gavriely N. Breath sounds. In: Methodology. Boca Raton, FL: CRC Press, 1995

6 Elphick HE, Ritson S, Rogers H, Everard ML. When a "wheeze" is not a wheeze - analysis of breath sounds in infancy. Eur Respir $72000 ; 17$.

7 Thornton AJ, Morley CJ, Hewson PH, Cole TJ, Fowler MA, Tunnacliffe JM. Symptoms in 298 infants under 6 months old, seen at home. Arch Dis Child 1990;65:280-5.

8 Luyt DK, Burton P, Brooke AM, Simpson H. Wheeze in preschool children and its relation with doctor diagnosed asthma. Arch Dis Child 1994;71:24-30.

9 Asher MI, Keil U, Anderson HR, et al. International study of asthma and allergies in childhood (ISAAC): rationale and methods. Eur Respir f 1995;8:483-91.

10 Cane RS, Ranganathan SC, McKenzie SA. What do parents of wheezy children understand by "wheeze"? Arch Dis Child 2000;82:327-32.

11 English M, New L, Peshu N, Marsh K. Video assessment of simple respiratory signs. $B M \mathcal{F}$ 1996;313:1528.

12 Powell CVE, Primhak RA. Stability of respiratory symptoms in unlabelled wheezy illness and nocturnal cough. Arch Dis Child 1996;75:385-91 